\title{
EVENTOS DE CHUVA ASSOCIADOS COM DESASTRES NATURAIS NA COSTA DO ESTADO DE SÃO PAULO
}

\author{
Guilherme Mansano Santos ${ }^{(\mathrm{a})}$, Jonas Teixeira Nery(b) \\ (a) Aluno do bacharelado em Geografia/ Unesp - Campus Ourinhos, gui.mansano92@gmail.com \\ (b) Professor Adjunto do curso de Geografia/ Unesp - Campus Ourinhos, jonas@ ourinhos.unesp.br
}

\section{Eixo: GEOGRAFIA FISICA E DESASTRES NATURAIS}

\begin{abstract}
Resumo/
O objetivo deste trabalho foi realizar um levantamento e mapeamento de eventos extremos de chuva, associando estes eventos a desastres naturais em áreas vulneráveis e/ou de risco na região metropolitana da baixada santista e litoral norte do estado de São Paulo. Após eventos extremos de chuva, associados à Zona de Convergência de Umidade (ZCOU), a Zona de Convergência do Atlântico Sul (ZCAS) e o El Niño Oscilação Sul (ENOS - Fase quente) intensos, essa região sofreu inúmeros desastres naturais, entre eles enchentes, alagamentos, deslizamentos, escorregamentos e desmoronamentos, agravados pela ação antrópica. Partindo da premissa de que o litoral paulista é uma área suscetível a desastres naturais, foi coletado e analisado dados de chuvas da série histórica de 1980 a 2010 para aferir os eventos de chuva, sua frequência e intensidade.
\end{abstract}

Palavras chave: Baixada Santista, litoral norte, evento de chuva, desastres naturais, El Niño.

\section{INTRODUÇÃO}

A Região Metropolitana da Baixada Santista está localizada no centro da porção atlântica do estado de São Paulo e é constituída por nove municípios, sendo eles Bertioga, Cubatão, Guarujá, Itanhaém, Mongaguá, Peruíbe, Praia Grande, São Vicente e a sede regional Santos.

Possuindo 65 km contínuos de extensão litorânea, a Região Metropolitana da Baixada Santista é composta por duas unidades morfológicas, as Escarpas da Serra do Mar e a Planície litorânea.

Datado desde a época da colonização, a urbanização na Baixada Santista é tida como uma das, senão a mais antiga do Brasil, sendo que atualmente a Baixada Santista se mostra densamente urbanizada tanto na faixa próxima ao mar quanto na faixa próxima às encostas da Serra do Mar. De acordo com o Censo Demográfico de 2010 (IBGE), a população da Baixada Santista era de 4 \% da população estadual, o que equivalia a, aproximadamente, 1,7 milhão de habitantes, embora este número chegue a triplicar nos meses de férias (julho e dezembro).

O litoral Norte, por sua vez, dividido em cinco sub-regiões, sendo que os municípios integrantes do litoral norte encontram-se na Sub-Região 5, representada por Caraguatatuba, Ilha Bela, São Sebastião e Ubatuba. 


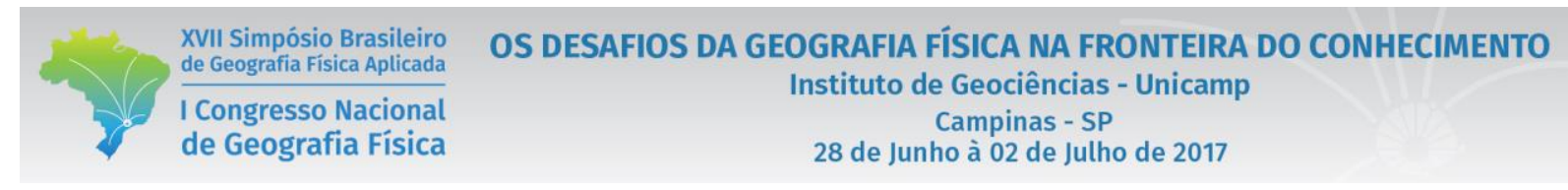

Devido à sua localização latitudinal, a precipitação pluviométrica na Baixada Santista e litoral Norte, caracterizam-se pela atuação de dois tipos de sistemas atmosféricos: aqueles que associam características tropicais, os quais são originados sobre a região amazônica e provocam precipitações do tipo convectivas e também os sistemas típicos de latitudes médias e altas, geradores das precipitações do tipo ciclônica.

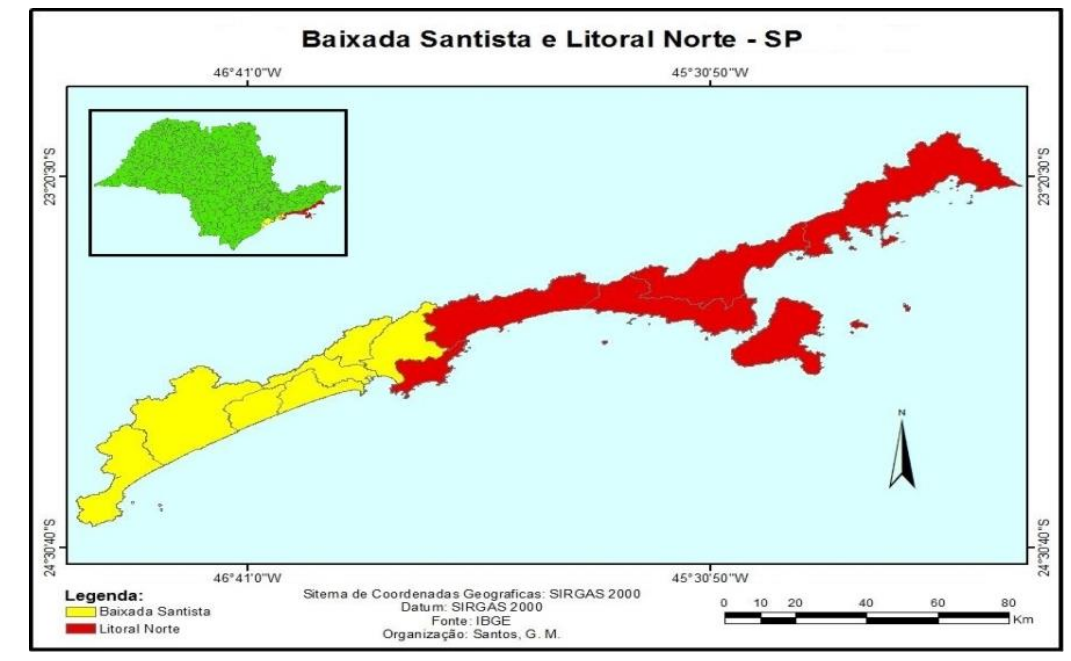

Figura 1 - Localização da baixada santista e litoral norte de São Paulo.

Fonte: Elaborado pelo autor.

Levando-se em conta as características geográficas, socioeconômicas, ambientais e políticoadministrativas dos municípios da Baixada Santista e litoral Norte, percebe-se que os mesmos estão vulneráveis e suscetíveis a desastres. Segundo a United Nations International Strategy for Disaster Reduction (UNISDR, 2009), desastre é uma grave perturbação ou distúrbio do funcionamento de uma comunidade ou sociedade, envolvendo perdas econômicas, materiais, ambientais e principalmente humanas, com grande extensão, de forma que o ônus vai além da capacidade da comunidade ou sociedade afetada de se recuperar por conta própria.

Conforme o passar das décadas, a transformação que o homem exercia no meio ao qual estava inserido estava ligada diretamente com o desenvolvimento e progresso social, porem estas vêm acompanhadas de efeitos nocivos e muitas vezes catastróficos para o meio ambiente.

A partir da análise das isolinhas pode-se observar que o litoral paulista é um ambiente de altos níveis de precipitação, e os desastres naturais são frequentes, uma vez que há tendência aos riscos decorrentes dos deslizamentos de terra e enchentes, representando os principais tipos de desastres que ocorrem nesta região. Estes fenômenos ocorrem normalmente associados a eventos pluviométricos intensos e prolongados, nos períodos chuvosos que correspondem às estações de primavera e verão na região Sudeste (TOMINAGA, 2009). 


\section{OS DESAFIOS DA GEOGRAFIA FÍSICA NA FRONTEIRA DO CONHECIMENTO \\ Instituto de Geociências - Unicamp \\ Campinas - SP \\ 28 de Junho à 02 de Julho de 2017}

\section{MATERIAIS E MÉTODOS}

Os procedimentos metodológicos adotados neste estudo consistem em levantamento e tratamento de dados meteorológicos da Agência Nacional de Água (ANA), através do site HIDROWEB, para a caracterização pluviométrica da área estudada, para que assim possa ser realizada a análise dos eventos de chuva e sua concentração. Para a tabulação dos dados foi usado o programa Excel.

Os critérios para seleção das estações pluviométricas foram a espacialização e a disponibilidade de dados de cada estação, dentro do período estudado. Foram analisadas as chuvas na área de estudo no período de 1980 a 2014. Os dados foram analisados em escala diária, mensal e anual.

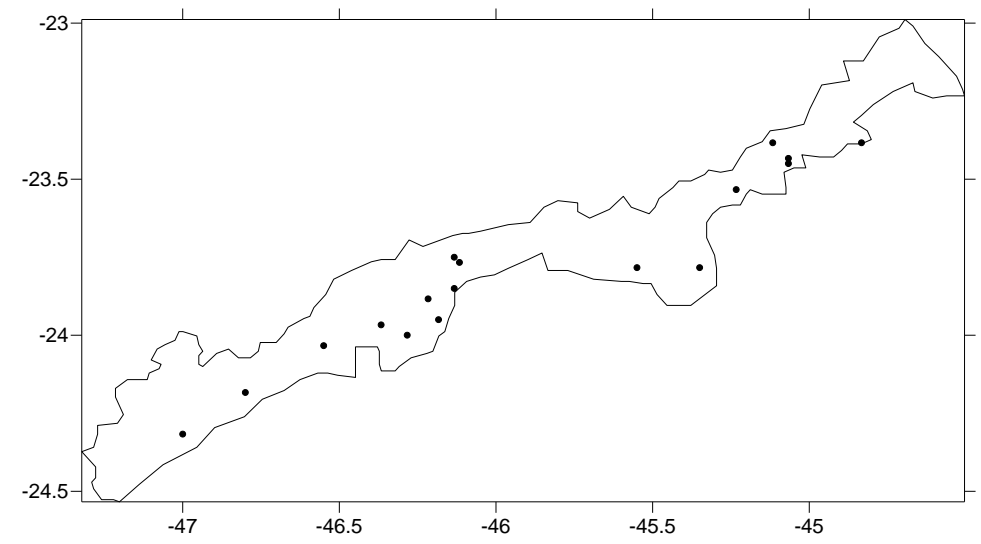

Figura 2 - Localização das séries pluviométricas na área de estudo.

Fonte: Elaborado pelo autor.

Fazendo uso de rotinas de análise de qualidade dos dados foi possível homogeneizá-los, preenchendo eventuais falhas na série histórica. Os dados pertinentes à ocorrência de desastres naturais foram obtidos a partir de acervos do site da Defesa Civil. Em seguida, serão associados os períodos de ocorrência de desastres naturais com eventos climáticos extremos.

Foi utilizada a Geoestatística para o traçado das isolinhas, que foram interpoladas a partir do método de krigagem (Krige). Para elaboração dos mapas foram utilizados os SIGs ArcGis e Surfer 8.

\section{DISCUSSÃO DOS RESULTADOS}

Na Figura 3, observam-se valores elevados para a média anual de precipitação pluviométrica que abrange o litoral do estado de São Paulo, com médias que atingem 2.200 mm. 


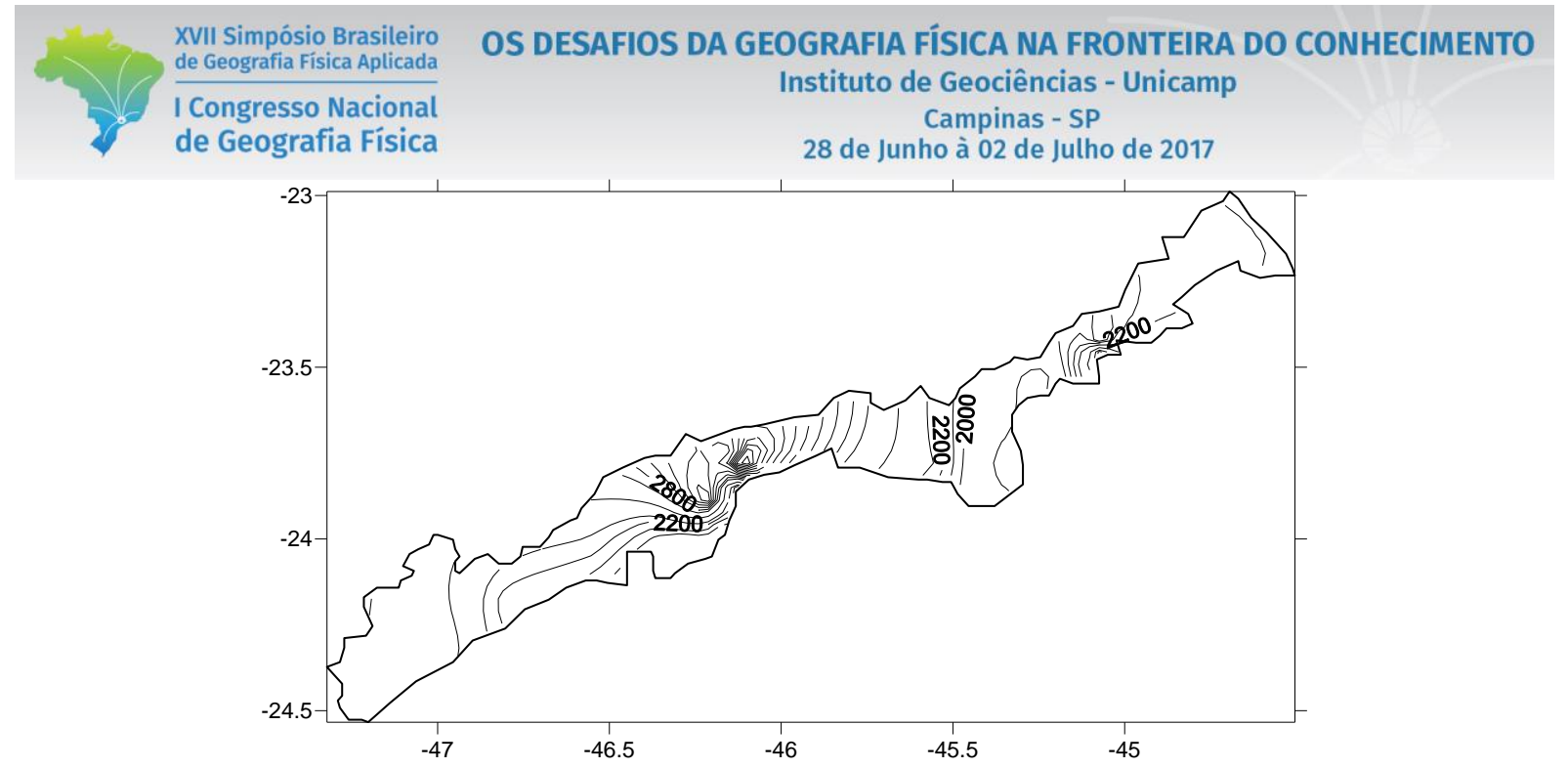

Figura 3 - Média de precipitação, para o período analisado.

Fonte: Elaborado pelo autor.

A grande concentração populacional do litoral paulista faz com que ele seja bastante sensível às condições climáticas. A concentração das chuvas no litoral é fortemente influenciada pelos atributos geográficos que caracterizam a região e pela dinâmica dos sistemas atmosféricos que atuam na área.

Foram analisadas anomalias na precipitação da área de estudo e em determinados anos foi possível encontrar valores negativos, mostrando que as chuvas foram moderadas e até mesmo abaixo da média, o que indica um ano particularmente seco, como é o caso de 1997. No entanto, encontrou-se também anomalias de precipitação muito elevada, como é o caso do ano de 2010 onde os valores de precipitação ficaram acima da média climatológica 600 e $800 \mathrm{~mm}$.

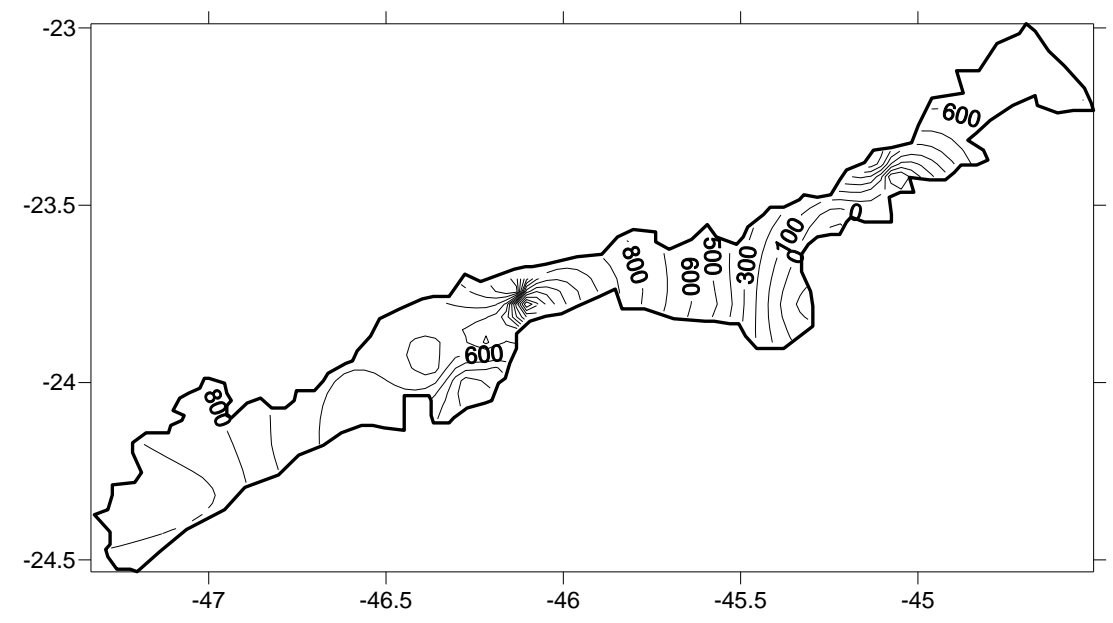

Figura 4 - Anomalia da chuva de 2010.

Fonte: Elaborado pelo autor. 


\section{CONCLUSÃO}

Após o estudo dos dados gerados para análise da precipitação e por conseqüência os eventos de chuva na região metropolitana da baixada santista e litoral norte, o que se pode perceber sobre o regime pluviométrico nos territórios estudados é que seus valores são bem elevados. Isso se dá principalmente devido sua localização geográfica, limitado pela Serra do Mar a leste e o oceano Atlântico a oeste. Ambos contribuem para um maior acúmulo de energia e umidade, que, por sua vez, intensificam os eventos de chuva.

Embora esta pesquisa não tenha sido concluída, a partir dos levantamentos e das análises propostas neste trabalho, foi possível compreender que a baixada santista e litoral norte do estado de São Paulo apresentam as maiores ocorrências de enchentes e deslizamentos. Entende-se que na região de estudo as atividades e dinâmicas atmosféricas têm relação direta e intrínseca com estes desastres naturais.

Tanto as enchentes quanto os movimentos de massa são originados a partir de eventos de chuva considerados extremos, tanto por sua intensidade quanto sua duração, isto aliado a topografia, geologia e fatores biológicos do local são predicativos perfeitos para ocorrência de desastres naturais, que devido à ação antrópica acentuada e ocupação de áreas suscetíveis, acarretam em danos econômicos e sociais.

Haja vista a particularidades da área de ocorrência dos desastres, um estudo retrospectivo dos locais afetados se faz necessário para melhor compreensão dos de desastres, bem como sua frequência e abrangência, a fim de buscar o entendimento de como funcionam os processos que acabam em desastres naturais e afetam a vida de várias pessoas. Feito isso, com estes resultados em mãos espera-se que possam ser feitas análises cujo objetivo seja ações mitigadoras ou redutoras de desastres.

\section{Bibliografia}

QUADRO, M. F. L. Estudo de episódios de Zonas de Convergência do Atlântico Sul (ZCAS) sobre a América do Sul. 1994. 94f. Dissertação (Mestrado em Meteorologia)- Instituto Nacional de Pesquisas Espaciais, São José dos Campos, 1994.

SANSIGOLO, C. A.; NERY, J. T. Análise de fatores comuns e agrupamentos das precipitações nas Regiões Sudeste e Sul do Brasil. In: CONGRESSO BRASILEIRO DE METEOROLOGIA, 10; CONGRESSO DA FILISMET, 7, Brasília, 1998. Anais... Brasília: SBMET, 1998.

TOMINAGA, L. K.; SANTORO, J.; AMARAL, R. Desastres naturais: conhecer para prevenir. São Paulo: Instituto Geológico, 2009. 